\title{
Correction to: Levels of metals and persistent organic pollutants in traditional foods consumed by First Nations living on-reserve in Canada
}

\author{
Hing Man Chan ${ }^{1}$ (D) Kavita Singh ${ }^{1} \cdot$ Malek Batal $^{2,3}$ (D) Lesya Marushka ${ }^{4} \cdot$ Constantine Tikhonov $^{4} \cdot$ Tonio Sadik $^{5} \cdot$ \\ Harold Schwartz ${ }^{4} \cdot$ Amy ng $^{2} \cdot$ Karen Fediuk $^{1}$
}

Published online: 29 July 2021

(C) The Canadian Public Health Association 2021

\section{Correction to: Canadian Journal of Public Health (2021) 112 (Suppl 1):S81-S96 https://doi.org/10.17269/s41997-021-00495-7}

This article was updated to correct author Lesya Marushka's name.

Publisher's note Springer Nature remains neutral with regard to jurisdictional claims in published maps and institutional affiliations.

The online version of the original article can be found at https://doi.org/ 10.17269/s41997-021-00495-7

Hing Man Chan

laurie.chan@uottawa.ca

1 Department of Biology, University of Ottawa, 30 Marie Curie, Ottawa, ON K1N 6 N5, Canada

2 Département de Nutrition, Faculté de Médecine, Pavillon Liliane de Stewart, Université de Montréal, C.P. 6128, succ. Centre-Ville, Montréal, QC H3T 1A8, Canada

3 Centre de recherche en santé publique de l'Université de Montréal et du CIUSS du Centre-sud-de-l'Île-de-Montréal (CReSP), 7101 avenue du Parc, Montréal, QC H3N 1X7, Canada

4 First Nations and Inuit Health Branch, Indigenous Services Canada, Ottawa, ON, Canada

5 Assembly of First Nations, 55 Metcalfe Street, Suite 1600, Ottawa, ON K1P 6L5, Canada 